\title{
The CRF System Mediates Increased Passive Stress-Coping Behavior Following the Loss of a Bonded Partner in a Monogamous Rodent
}

\author{
Oliver J Bosch",', Hemanth P Nair', Todd H Ahern², Inga D Neumann' and Larry J Young ${ }^{2}$ \\ 'Department of Behavioural Neuroendocrinology, University of Regensburg, Regensburg, Germany; ${ }^{2}$ Department of Psychiatry, Center for \\ Behavioral Neuroscience, Yerkes National Primate Research Center, Emory University, Atlanta, GA, USA
}

\begin{abstract}
Social relationships significantly influence physiology and behavior, including the hypothalamo-pituitary-adrenal axis, anxiety, and mental health. Disruption of social bonds through separation or death often results in profound grieving, depression, and physical illness. As the monogamous prairie vole forms enduring, selective pair bonds with the mating partner, they provide an animal model to study the physiological consequences of pair bonding and, thus, the loss of the bonded partner. Male prairie voles were paired with a novel female or male sibling. After 5 days, half of the males of each group were separated from the partner. Elevated plus-maze, forced swim, and tail suspension tests were used to assess anxiety-like and passive stress-coping behaviors indicative of depressive-like behavior. Following 4 days of separation from the female but not the male partner, experimental males displayed increased passive stress-coping. This effect was abolished by long-term intracerebroventricular infusion of a nonselective corticotropin-releasing factor (CRF) receptor antagonist without disrupting the bond itself. Both CRF type I and 2 receptors were involved in the emergence of passive stress-coping behavior. Furthermore, pairing with a female was associated with elevated CRF mRNA in the bed nucleus of the stria terminalis, and partner loss elicited a pronounced increase in circulating corticosteroid and adrenal weight. We speculate that the CRF system may mediate an aversive affect following separation from the female partner, which may facilitate proximity seeking between the pair-bonded individuals. Hence, the prairie vole model may provide insights into brain mechanisms involved in the psychopathological consequences of partner loss.
\end{abstract}

Neuropsychopharmacology (2009) 34, |406-14I5; doi:I0.1038/npp.2008.154; published online I5 October 2008

Keywords: prairie vole; passive stress-coping; forced swim test; tail suspension test; elevated plus-maze; hypothalamo-pituitary-adrenal axis

\section{INTRODUCTION}

There is increasing evidence that social bonds have a positive impact on health and buffer against stressors (Kikusui et al, 2006). In contrast, the absence or sudden disruption of those bonds increases susceptibility to diseases (House et al, 1990; Kirschbaum et al, 1995; Uchino et al, 1996; Capitanio et al, 1998; for review see Biondi and Picardi, 1996; DeVries et al, 2003), including depression (Zisook et al, 1997; Watanabe et al, 2004; Grippo et al, $2007 a, b)$. In humans, bereavement is a highly disruptive experience that is usually followed by a painful period of acute grief (Shear and Shair, 2005). Thus, understanding the neurobiological consequences of partner loss, particularly with respect to increased susceptibility to depression, may

*Correspondence: Dr OJ Bosch, Department of Behavioural Neuroendocrinology, University of Regensburg, Universitätsstr. 31, Regensburg 93040, Germany, Tel: + 49941943 3076, Fax: + 49941943 3052, E-mail: oliver.bosch@biologie.uni-regensburg.de

Received 7 April 2008; revised 21 August 2008; accepted 22 August 2008 be informative for developing strategies for coping with the loss of a loved one.

Prairie voles (Microtus ochrogaster) have served as an excellent animal model for examining the neurobiological mechanisms underlying social bonding (Carter and Getz, 1993; Carter et al, 1995; Aragona and Wang, 2004) and for investigating the physiological consequences of social loss (Grippo et al, 2007a,b). Unlike $95 \%$ of all mammalian species, prairie voles are socially monogamous, forming enduring and selective pair bonds with their mates (Carter and Getz, 1993). Although the formation of pair bonds is thought to be based on brain circuitries mediating reward and reinforcement (Young and Wang, 2004; Nair and Young, 2006; Aragona et al, 2003, 2006), an aversion to prolonged partner separation may help preserve the bond over time by inducing proximity-seeking behaviors. Thus, we predicted that even a short separation from a partner may be aversive and lead to an alteration in emotionality as reflected by increased passive stress-coping or anxiety-like behavior in male voles. In fact, recent publications have shown that 4 weeks social isolation leads to increased passive coping in female prairie voles (Grippo et al, 2007a, b). 
The behavioral consequences of disrupting a pair bond could be associated with both the brain corticotropinreleasing factor (CRF) system and hypothalamo-pituitaryadrenal (HPA) axis. Chronic upregulation of the brain CRF system is thought to be important in the pathogenesis of various psychopathologies, including anxiety-like and depressive-like disorders (for review see Holsboer and Barden, 1996; Nemeroff, 1996; Keck, 2006). Reduced anxiety-like and depressive-like behaviors have been shown after blocking CRF receptors in rats (Liebsch et al, 1995; Bakshi et al, 2002; Hodgson et al, 2007) and in mice lacking CRF receptors (Timpl et al, 1998; Kishimoto et al, 2000; for review see Behan et al, 1996). Social support reduces the basal activity of the HPA axis as well as cortisol responses to psychological stressors in humans and in other species (Elliot, 1989; Kirschbaum et al, 1995; DeVries et al, 1997; Sachser et al, 1998; Thorsteinsson and James, 1999) and, thus, may also affect well-being (Elliot, 1989; Kikusui et al, 2006) by minimizing long-term exposure to increased levels of glucocorticoids (DeVries, 2002).

To examine the consequences of disruption of a pair bond and the potential involvement of the CRF system, we measured passive stress-coping as an indicator of depressive-like behavior and anxiety-like behavior in male prairie voles following a 3-5 day separation from a female partner or a male sibling. We then tested whether separation from a female partner increases plasma ACTH and glucocorticoid levels or brain CRF mRNA. Finally, we investigated the role of CRF receptors (CRF-R1 and CRF-R2) in the behavioral changes precipitated by the loss of a bonded partner.

\section{MATERIALS AND METHODS}

\section{Animals}

All animals were sexually naïve adult male and female prairie voles (70-100 days of age) from the laboratorybreeding colony originally derived from field-captured voles in Illinois, USA. After weaning at 21 days of age, subjects were housed in same-sex sibling pairs or trios under standard laboratory conditions $(14: 10 \mathrm{~h}$ light-dark cycle, lights on at $06: 00 \mathrm{~h} ; 20^{\circ} \mathrm{C}, 60 \%$ humidity and free access to water and Purina rabbit chow). All behavioral tests were performed between 08:00 and $12: 00 \mathrm{~h}$. In an attempt to minimize stress during the experimental paradigm, a careful cage change regimen was followed: animals were only exposed to new cages at the beginning of the pair housing and separation periods. Furthermore, approximately $1 / 3$ of the bedding from an animal's previous cage accompanied it to the new cage. The animal studies were conducted in accordance with the guidelines of the National Institute of Health and were approved by Emory University's Institutional Animal Care and Use Committee.

\section{Experimental Protocol}

Male voles were paired with either unfamiliar females or male siblings. In the male siblings group, only those siblings were paired which were housed separately from each other since weaning (49-79 days without contact). After 5 days, half of the voles of each group were separated. Twenty-four hour of cohabitation with a female - even without mating -is sufficient for the induction of a partner preference, which is a laboratory proxy for pair-bond formation (Williams et al, 1992). Prairie vole females do not display regular ovarian cycles, but are reliably induced into estrus 24-48 $\mathrm{h}$ following cohabitation with a male as a consequence of exposure to male urine. Females will mate for a 24-h period during estrus (Roberts et al, 1998), and mating does not occur after this period. Therefore, the stage of the estrus cycle was not assessed in the females before cohabitation with the male. Each vole underwent only one of the Experiments A-E. The details for each experiment are illustrated in Figure 1. We first sought to determine whether disruption of a pair bond in male prairie voles would result in changes in passive stress-coping (Experiment A) and anxiety-related behavior (Experiment B). In Experiment C we investigated whether the pairing and separation alters basal plasma levels of stress hormones. We then determined whether the CRF system is linked to partner loss-induced passive stress-coping by nonselective blocking of brain CRF receptors (Experiment D). Finally, Experiment E employed selective CRF-R1 and CRF-R2 antagonists to identify which CRF-R type underlies this link.

Forced swim test. Male voles were exposed to the forced swim test (FST; Porsolt et al, 1977) in a single test session as this has been shown to reveal differences in passive stresscoping in rats (Liebsch et al, 1999; Overstreet et al, 2004, 2008) and mice (Borsini and Meli, 1988; Oshima et al, 2003; for review see Cryan and Mombereau, 2004; Cryan et al, 2005). Animals were forced to remain for $5 \mathrm{~min}$ in a 41 glass

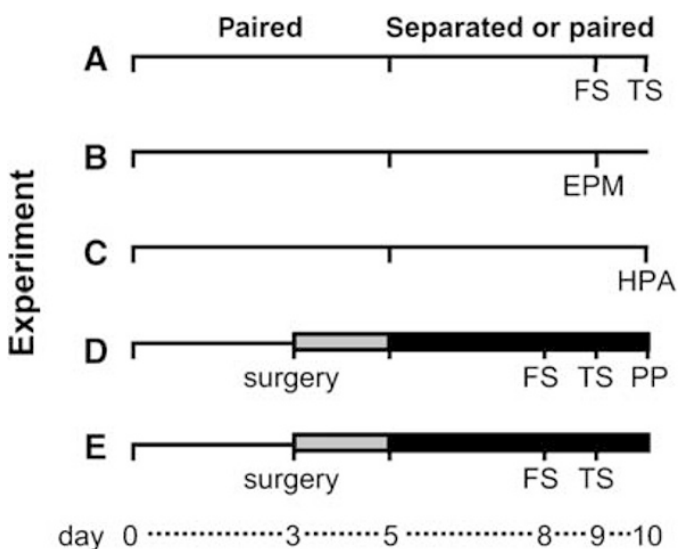

Figure I Testing schedules of the five experimental approaches (A-E). Male prairie voles were co-housed and allowed to form a partner bond. After 5 days, half of the males of each group were separated from the partner; animals from paired groups stayed with their partner. On the ninth day after pairing, ie the fourth day after separation (A, B) or on the eighth day after pairing, ie the third day after separation (D, E), testing for behavioral effects started, or voles were left undisturbed until the tenth day after first pairing, ie the fifth day after separation in the particular groups, to take blood samples and brains under basal conditions (C). In Experiments $(\mathrm{D}, \mathrm{E})$, osmotic minipumps were implanted after 3 days of pairing delivering Ringer's solution until day 5 of pairing (grey bars) when half of the animals were separated followed by CRF receptor antagonist lasting until the end of the experiment (black bars). EPM=elevated plus-maze; FS=forced swim test; HPA = hypothalamo-pituitary-adrenal axis; PP = partner preference test; $\mathrm{TS}=$ tail suspension test. 
beaker $(15 \mathrm{~cm}$ in diameter) filled to a height of $20 \mathrm{~cm}$ with tap water $\left(23 \pm 1^{\circ} \mathrm{C}\right)$. The behavior of the voles was scored by a trained observer blind to the animals' treatment. The following behaviors were recorded according to our previous studies in rats (eg Ebner et al, 2005) using an automatic timer software package (Stopwatch +; Center for Behavioral Neuroscience, Atlanta, GA: downloadable at http://www.cbn-atl.org/research/behavioralcore.shtml): (1) struggling, defined as movements during which the forelimbs break the water's surface; (2) swimming, defined as movements of the fore and hind limbs resulting in forward motion without breaking the water surface, including diving, and (3) floating, defined as the behavior during which the animal uses limb movement to maintain its equilibrium without any movement of the trunk as an indicator of passive stress-coping.

Tail suspension test. The procedure used was similar to that described by Steru et al (1985). Male voles were suspended by their tail using adhesive tape to an aluminium stick (diameter $1 \mathrm{~cm}$ ) and hung in the middle of a black covered box $\left(40 \times 40 \times 40 \mathrm{~cm}^{3}\right)$ approximately $80 \mathrm{~cm}$ above the ground. The duration of immobility (passive hanging indicative of passive stress-coping) during a 5-min test period was recorded using Stopwatch + software (see above).

Elevated plus-maze. In the elevated plus-maze (EPM) test, a conflict situation is created between the animal's exploratory drive and its innate fear of open and exposed areas as demonstrated in rats (Pellow et al, 1985; Liebsch et al, 1998) and voles (Hendrie et al, 1997; Insel et al, 1995; Pitkow et al, 2001). The vole plus-maze consisted of an elevated (height: $100 \mathrm{~cm}$ ) plus-shaped aluminium platform with two closed $(40 \mathrm{~cm}$ high walls out of dark PVC, $<20$ lux) and two open arms (each $60 \times 10 \mathrm{~cm}, 80 \mathrm{lux}$ ), connected at the center by a neutral zone $(10 \times 10 \mathrm{~cm})$. Before a vole was placed on the EPM, the surface of the maze was cleaned with water containing a low concentration of a detergent and dried. The vole was placed in the neutral zone with its head facing a closed arm. The following parameters were recorded with a video/computer system (Plus-maze V2.0; Ernst Fricke, Germany) by a trained observer blind to the animals' treatment during the 5-min exposure according to our own studies in rats (eg, Neumann et al, 1998; Bosch et al, 2005): (1) percentage of time spent on the open arms $v s$ total time on all arms, (2) percentage of entries into open arms $v s$ entries into all arms, and (3) the number of entries into closed arms. (1) and (2) are indicative of anxiety-like behavior, (3) represents locomotion.

Partner preference test. To reveal whether our pharmacological manipulation of the CRF system might influence the expression of a partner preference after 5-days of cohabitation, we tested the males from Experiment D (nonselective CRF-R antagonist) in the partner preference test as previously described (Williams et al, 1992; Winslow et al, 1993). Numbers of cage entries were counted to reveal differences in locomotor activity. On the next day, voles were killed and the brains collected for confirmation of cannula placement. The injection site was verified by injecting ink by the implanted brain infusion kit targeting the lateral ventricle, removal of the brain, and a vertical cut through the brain.

\section{Detection of ACTH and Corticosterone}

Between 0900 and $1100 \mathrm{~h}$, male voles were briefly anesthetized with isoflurane, and immediately decapitated using scissors within $2 \mathrm{~min}$ after removal from the cage. Trunk blood $(\sim 0.2 \mathrm{ml})$ was collected on ice in EDTA-coated tubes complemented by aprotinin $(10 \mu \mathrm{l}$ per tube; Trasylol, Bayer AG, Leverkusen, Germany). The blood was centrifuged at $4{ }^{\circ} \mathrm{C}, 5000$ r.p.m. for $5 \mathrm{~min}$, and plasma was aliquoted and stored at $-80^{\circ} \mathrm{C}$ until assay. Plasma ACTH and corticosterone were measured in 50 and $10 \mu$ plasma samples, respectively, using commercially available kits (ICN, Costa Mesa, USA) according to the respective protocols.

\section{In Situ Hybridization for CRF mRNA}

In situ hybridization for CRF was performed using a rat CRF ${ }^{35} \mathrm{~S}$ riboprobe as described previously (Ressler et al, 2002). In a pilot study, slides were exposed to X-ray film and a densitometric analysis was performed for the central nucleus of the amygdala, lateral bed nucleus of the stria terminalis, medial bed nucleus of the stria terminalis (mBNST), and paraventricular nucleus (PVN) of the hypothalamus. As differences in signal between groups were detected only in the mBNST, we performed a more quantitative analysis of CRF expression in this area by counting silver grains over cells of emulsion-dipped slides. The slides were exposed to photographic emulsion (Kodak NTB-2) for 4 days and counterstained with cresyl violet before coverslipping. Silver grains in the mBNST were quantified using the AIS Image Analysis software's grain counting feature. Images of the area of interest were taken through a $\times 40$ objective, and digitized with a MTI CCD72 camera. The numbers of grains in approximately 15 clusters over cells in the mBNST were counted using a 40 pixel diameter circular cursor setting for each cluster. Grain counts from a proportionate area in the caudate putamen were taken as a background reading. For the mBNST and background readings, bilateral grain counts from three adjacent sections were taken and averaged. The background reading for each section was subtracted from the reading for the mBNST.

\section{Long-Term Intracerebroventricular Administration of CRF-R Antagonists}

On the third day of pairing an intracerebroventricular (i.c.v.) osmotic minipump (Model 1007D, infusion flow rate: $0.5 \mu \mathrm{l} / \mathrm{h}$; Brain Infusion Kit 3; fixant Loctite 454; Alzet Osmotic Pumps, Cupertino, CA, USA) was stereotaxically implanted (coordinates for the lateral ventricle: nose bar, $2.5 \mathrm{~mm}$; AP, $0.6 \mathrm{~mm}$; ML, $1.0 \mathrm{~mm}$; DV, $3.0 \mathrm{~mm}$ ) under isoflurane anesthesia (Novaplus; Hospira Inc., Lake Forest, IL, USA) as described before (Torner et al, 2001). The cannula was connected to the osmotic minipump through PE-20 tubing filled with either Ringer's solution or Ringer containing (1) the nonspecific CRF-R antagonist d-phe-CRF 
(14.1 pmol/h; Bachem, Montreal, Canada; Experiment D) or (2) the selective antagonist for CRF-R1 (CP-154526; $137 \mathrm{pmol} / \mathrm{h}$; generously provided by $\mathrm{Dr}$ Michael Owens, Emory University, Atlanta, USA) or CRF-R2 (Astressin-2B; $12.4 \mathrm{pmol} / \mathrm{h}$; Sigma-Aldrich, St. Louis, USA; Experiment E). Infusion of each antagonist was timed such that the treatment actually began $48 \mathrm{~h}$ after surgery, the day that half of the animals were separated. To accomplish this, the PE-20 tubing extending from the osmotic minipump was filled with enough Ringer's solution to last for up to $44 \mathrm{~h}$ (from surgery to the end of the 5-day cohabitation period). To prevent diffusion between the Ringer's solution and the CRF-R antagonist solution, a small air bubble separated the two solutions in the tubing. At the end of the surgery, animals received $0.01 \mathrm{ml}$ i.p. analgesia (buprenorphine; Buprenex, Henry Schein Inc.). Afterwards, all male voles were placed on a piece of cotton wool in the original home cage with the female partner. Recovery of the animals was monitored until animals were fully awake. At the end of the experiment animals were killed and cannula placement was verified by infusion of black ink into the cannula and adrenals were removed and weighed.

\section{Statistics}

Data are presented as mean + SEM. Either a one-way ANOVA (factor CRF-R type 1 or 2 antagonist), two-way ANOVA (factors partner type (sibling/female); separation condition (paired/separated); treatment (vehicle/antagonist)) or three-way ANOVA (factors separation condition; treatment; female type (partner/stranger)) was performed for all experiments. All interactions were followed by Newman-Keuls post hoc tests for pair-wise comparisons. Significance was accepted at $p<0.05$. All statistics were performed using GB-Stat 10.0 (Dynamic Microsystems, Silver Springs, USA).

\section{RESULTS}

\section{Isolation from a Female Partner Induces Passive Stress-Coping Behavior}

Experiment $A$. During the FST, the time spent floating differed among groups (partner type (female or male sibling) $\times$ separation condition (paired or separated) interaction: $F_{1,34}=9.38, p=0.004$; Figure $2 \mathrm{a}$ ). Males separated from a female partner displayed significantly more floating behavior $(p<0.01)$ relative to males that remained with their female partner, and males that either remained with or were isolated from their sibling partner. In the tail suspension test (TST), we found a significant interaction between partner type and separation condition $\left(\mathrm{F}_{1,33}=18.1\right.$, $p=0.0002$; Figure 2b). Males isolated from a female displayed significantly more immobility $(p<0.01)$ compared with males in the other treatment groups.

Experiment $B$. On the EPM, separation from the partner altered only one anxiety-related parameter, ie the percentage of entries into the open arms of the EPM decreased in the separated groups independent of the sex of the partner (two-way ANOVA; factor partner: $\mathrm{F}_{1,42}=5.48, p=0.02$; Figure $2 \mathrm{~d}$ ). However, the post hoc test revealed no further

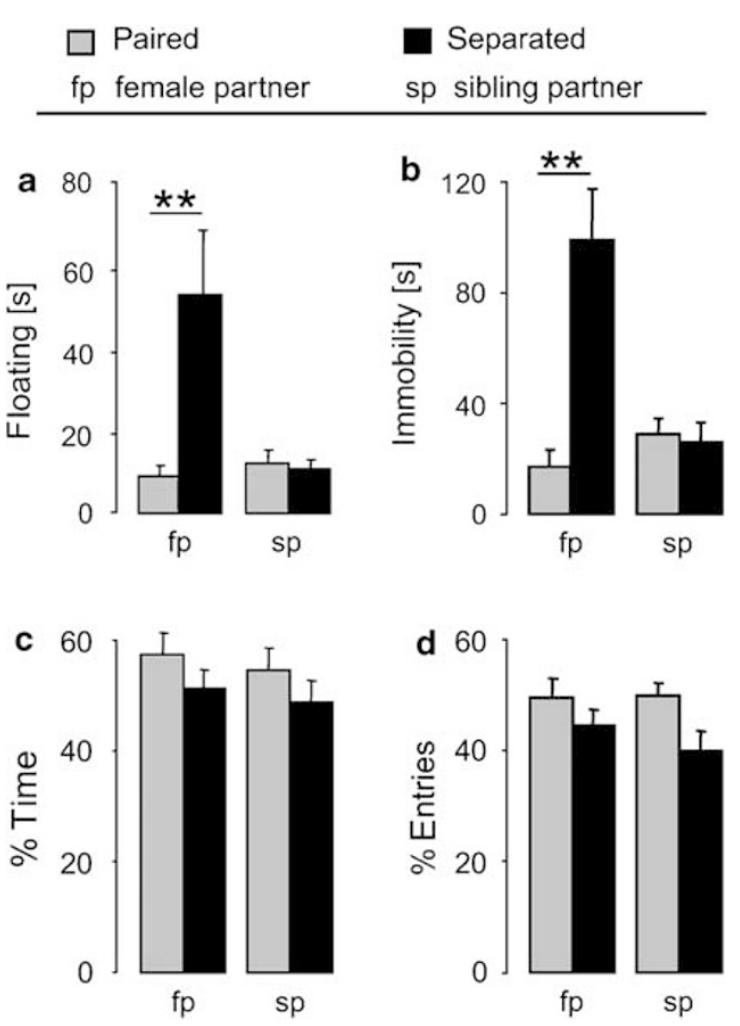

Figure 2 Effect of partner separation on passive stress-coping behavior in (a) the forced swim test and (b) the tail suspension test as well as (c, d) anxiety-like behavior on the elevated plus-maze. Male voles were paired for 5 days with a female ( $f p$ ) or male sibling ( $s p)$. Half of the males were then separated from their cage-mate (black bars) whereas the remaining half remained pair housed (grey bars) for 4-5 days before behavioral testing (from Experiment A (a, b) or Experiment B (c, d; see Figure I for details). Passive stress-coping behavior is reflected as the amount of time the animal spends inactive, ie floating (a) or immobile (b). Anxiety-like behavior is reflected as percentage of time spent in and percentage of entries into the open arms vs all arms (c, d). Numbers of animals included in the statistics were (a) female partner: $n=9$ in each group; sibling partner: $n=10$ in each group; (b) female partner: $n=9$ in each group; sibling partner paired: $n=9$; separated: $n=10$; (c, d) female partner paired: $n=10$; separated: $n=12$; sibling partner: $n=12$ in each group. Data are expressed as mean + SEM. *** $p<0.0$ I vs all other groups.

differences. Separation had no effect on the percentage of time spent on the open arms (partner $\times$ separation interaction: $F_{1,42}=0.02, p=0.90$; Figure $2 c$ ). There was no difference in the locomotion as reflected by entries into closed arms (female partner, paired: 12 \pm 2 ; separated: $13 \pm 1$; male partner, paired: $12 \pm 1$; separated: $12 \pm 1$; $\mathrm{F}_{1,42}=0.30, p=0.59$ ) between the groups.

\section{Isolation from a Female Partner Increases Basal Corticosterone Levels}

Experiment $C$. Basal plasma corticosterone levels significantly differed among groups (partner type $\times$ separation condition interaction: $\mathrm{F}_{1,35}=4.65, p=0.04$; Figure $3 \mathrm{a}$ ). Males separated from a female partner had higher corticosterone levels than males that remained with the female partner $(p<0.05)$. In the sibling-paired groups, no differences were found, paralleling recent findings by Grippo et al (2007a). 
Paired

fp female partner
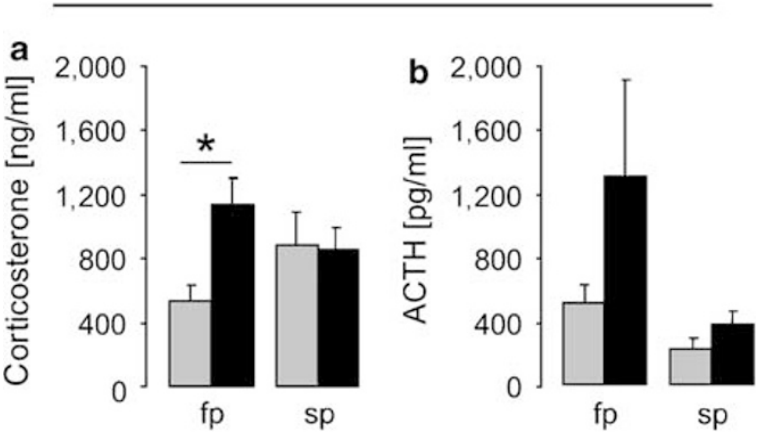

Figure 3 Effect of partner separation on basal plasma levels of corticosterone (a) and ACTH (b). Male voles were paired for 5 days with a female (fp) or male sibling (sp). Half of the males were then separated from their cage-mate (black bars) whereas the remaining half remained pair housed (grey bars) for 5 days (Experiment C; see Figure I for details). The voles were left undisturbed until the initial separation from the partner and no behavioral tests were performed. Numbers of animals included in the statistics were 10 per group. Data are expressed as mean + SEM. ${ }^{*} p<0.05$ vs respective female-paired group.

No significant differences were found for ACTH due to a high deviation in the female-paired, separated group (Figure 3b).

\section{Pairing with a Female Increased CRF mRNA in the mBNST}

In a pilot study (data not shown), we performed in situ hybridization for CRF mRNA in males paired or isolated from females or male siblings. Relative optical density measurements from in situ hybridization films revealed that among the central nucleus of the amygdala, lateral BNST, mBNST, and PVN of the hypothalamus, the only region showing differences across groups was the mBNST. To further verify this finding, brains of male voles from Experiment $\mathrm{C}$ were removed and processed for CRF mRNA in situ hybridization with emulsion dipping for grain counting. Grain cluster density in the mBNST is illustrated in Figure 4a. Two-way analysis of variance for partner type and separation condition revealed a main effect of partner type $\left(\mathrm{F}_{1,29}=6.68, p<0.02\right)$, such that males paired with a female or isolated from a female showed significantly higher CRF mRNA grain counts in the mBNST relative to males paired or isolated from a sibling (Figure $4 \mathrm{~b}$ ). Thus both groups of male with previous sexual experience displayed elevated CRF mRNA grain counts.

\section{Infusion of d-phe-CRF during the Isolation Period Blocks Separation-Induced Passive Stress-Coping Behavior}

Experiment D. Continuous i.c.v. infusion of the nonselective CRF-R antagonist, d-phe-CRF, which began on the day of isolation, resulted in differences among groups in the FST (factors separation $\times$ treatment: $\mathrm{F}_{1,34}=9.38, \quad p=0.004$; Figure 5a) and TST $\left(\mathrm{F}_{1,33}=18.1, p=0.0002\right.$; Figure $\left.5 \mathrm{~b}\right)$. d-phe-CRF-treated male voles separated from their female partner showed reduced floating $(p<0.01)$ and immobility $(p<0.01)$ in the FST and TST, respectively, relative to
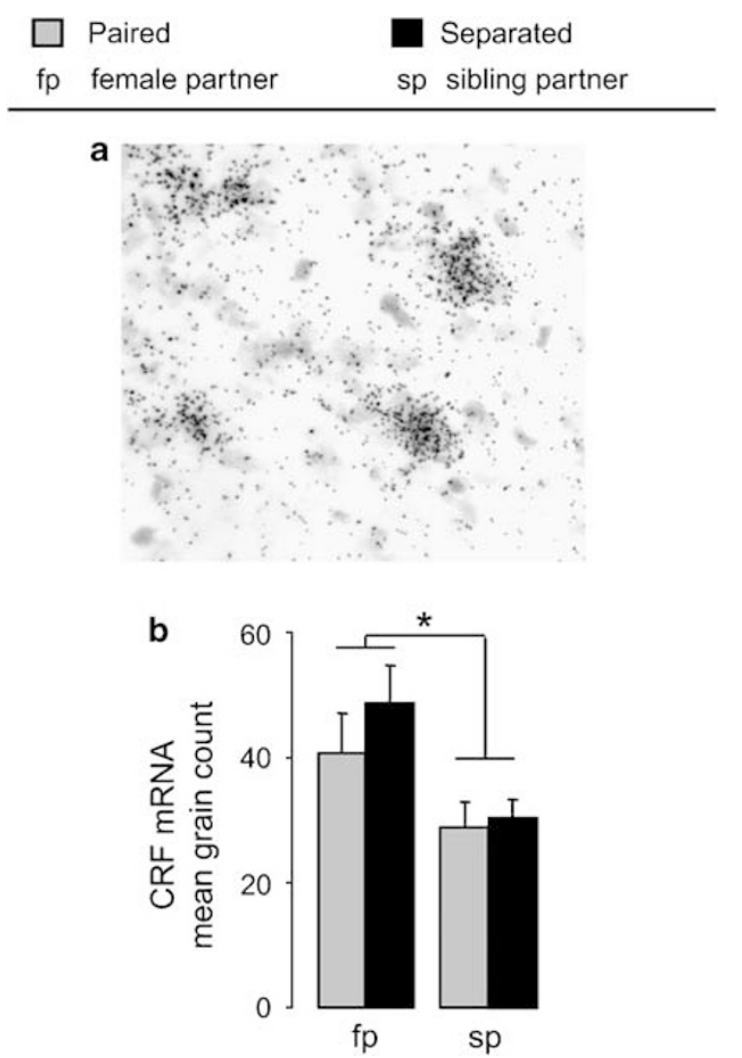

Figure 4 CRF mRNA expression in the mBNST. Clusters of grains in the region of the mBNST (a). Male voles (Experiment C; see Figure I for details) paired with a female (grey bars) or separated from a female (black bars) demonstrate higher CRF mRNA grains in the mBNST relative to males paired or separated from a sibling male (b). Data are expressed as mean + SEM. ${ }^{*} p<0.05$

vehicle controls (Figure $5 \mathrm{a}$ and $\mathrm{b}$ ). There was no effect of the d-phe-CRF on floating or immobility in males that were not separated from their female partner.

The partner preference test revealed that male voles paired with a female spent more time with the original female partner than with an unknown female (three-way ANOVA; main effect of partner type: $\mathrm{F}_{1,36}=54.9, p<0.0001$; Figure $5 \mathrm{c})$. There were no treatment $\left(\mathrm{F}_{1,36}=0.05, p=0.94\right)$, separation condition $\left(\mathrm{F}_{1,36}=1.08, p=0.30\right)$, or interaction effects, indicating that, once a pair bond is established, partner preferences are not disrupted by subsequent CRF antagonist treatment. Locomotor activity as reflected by the number of cage entries was similar between the groups independent of the treatment (paired VEH: $130 \pm 15$; d-pheCRF: $156 \pm 22$; separated VEH: $177 \pm 35 \mathrm{mg}$; d-phe-CRF: $121 \pm 20$; two-way ANOVA: $\mathrm{F}_{1,21}=2.08, p=0.17$ ).

The weight of the adrenal glands was higher after separation from the female partner (paired VEH: $148 \pm 10 \mathrm{mg} ; \quad$ d-phe-CRF: $146 \pm 5 \mathrm{mg} ;$ separated VEH: $196 \pm 11 \mathrm{mg}$; d-phe-CRF: $186 \pm 7 \mathrm{mg}$; two-way ANOVA; factor separation: $\left.F_{1,36}=26.0, p<0.0001\right)$ regardless of the treatment with d-phe-CRF (factor treatment: $\mathrm{F}_{1,36}=0.48, p=0.50$ ).

\section{Both CRF-R Types are Involved in Mediating Passive Stress-Coping Behavior after Separation}

Experiment E. Competitive receptor binding studies revealed that CP-154526 is selective for the prairie vole 


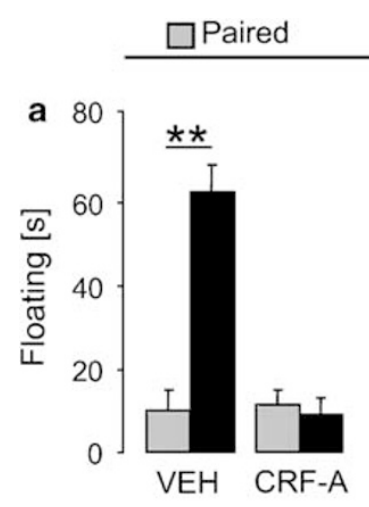

Separated

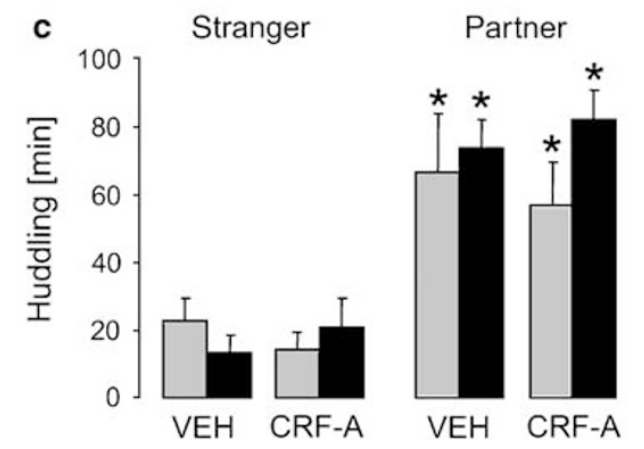

Figure 5 Effect of i.c.v. CRF-R antagonist (d-phe-CRF) treatment unspecific for receptor type I and 2 on passive stress-coping in (a) the forced swim test, (b) the tail suspension test, and (c) the partner preference test in female-paired male voles from Experiment D (see Figure I for details). Male voles were group-housed for 5 days with a female and constantly infused with CRF-A the following days while being still with the partner (grey bars) or separated 3-5 days (black bars). The amount of time the animals spend on passive stress-coping strategy, ie floating (a) or immobility (b). The partner preference (c) is represented by the time the male voles spent on huddling with either a female stranger or the bonding partner. Numbers of animals included in the statistics were paired VEH: 5; CRF-A: 4; separated VEH: 7; CRF-A: 6. Data are expressed as mean + SEM. ${ }^{*} p<0.0$ I vs all other groups. ${ }^{*} p<0.05$ vs huddling with stranger in same group.

CRF-R1 whereas Astressin-2B is selective for the prairie vole CRF-R2, as has been previously reported in the rat (see Supplementary Material). Both the CRF-R1- and the CRFR2-selective antagonists resulted in differences among groups in the FST (factors separation $\times$ treatment: $\mathrm{F}_{2,57}=6.36, p=0.003$; Figure $\left.6 \mathrm{a}\right)$ and TST $\left(\mathrm{F}_{2,58}=6.42\right.$, $p=0.003$; Figure 6b). Male voles separated from their female partner showed reduced floating in the FST when treated with i.c.v. CRF-R1 antagonist $(p<0.05)$ or CRF-R2 antagonist $(p<0.01)$ as well as reduced immobility (CRF-R1 antagonist: $p<0.01$; CRF-R2 antagonist: $p<0.01)$ in the TST, relative to the separated vehicle control (Figure $6 \mathrm{a}$ and b). There was no effect of the CRF-R antagonists on floating or immobility in males that were not separated from their partner.

\section{DISCUSSION}

In humans, long-term separation from the partner, eg due to its death, has been shown to increase the risk for depression (for review see Shear and Shair, 2005). Here we show for the first time that male prairie voles separated

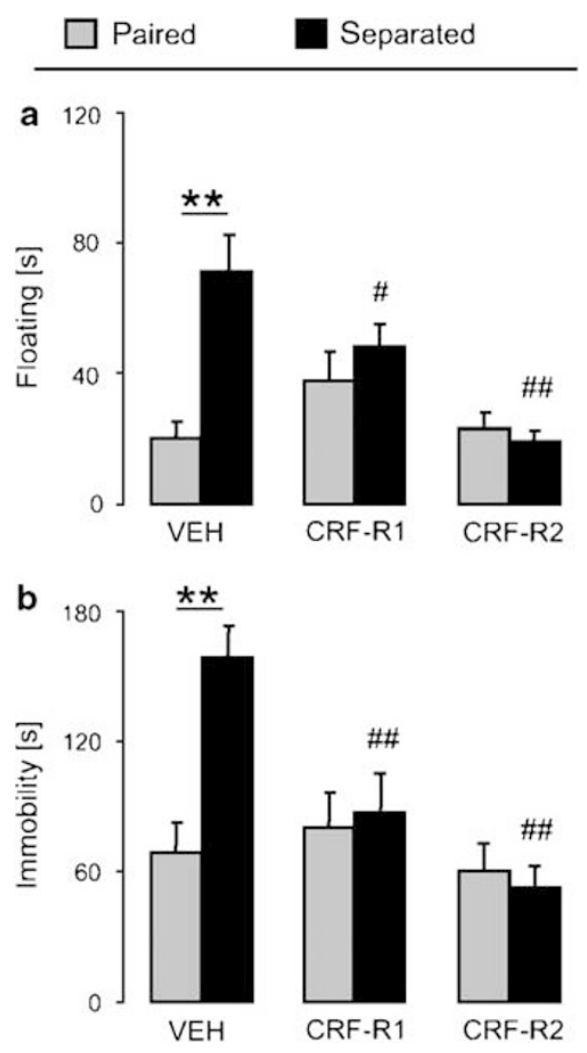

Figure 6 Effect of i.c.v. CRF-RI (CP-I54526) or CRF-R2 (Astressin-2B) antagonist treatment on passive stress-coping in (a) the forced swim test and (b) the tail suspension test in female-paired male voles from Experiment E (see Figure I for details). Male voles were group-housed for 5 days with a female and constantly infused with CRF-RI or -R2 antagonist the following days when still with the partner (grey bars) or separated 3-4 days (black bars). The amount of time the animals spend on passive stress-coping strategy is reflected as floating (a) or immobility (b). Numbers of animals included in the statistics were paired VEH: I0; CRF-RI: 9; CRF-R2: 9; separated were 10 per group. Data are expressed as mean + SEM. ${ }^{*} * p<0.0$ I vs respective female-paired group; ${ }^{\# \#} p<0.0$ I, ${ }^{\#} p<0.05$ vs vehicle-treated separated group.

from a female partner display increased passive stresscoping strategy in the FST and the TST, indicative of depressive-like behavior in rodents (Porsolt et al, 1977; Armario et al, 1988; Martí and Armario, 1993). Importantly, this effect was not present in males that remain paired with a female, paired with a male sibling unknown since weaning, or isolated from such a male sibling and, thus, emphasize the significant consequences of the loss of a bonded partner for male prairie voles. It is important to note that previous studies have shown that in sexually naïve female prairie voles long-term social isolation (4 weeks) increases passive stress-coping behavior (Grippo et al, $2007 \mathrm{a}, \mathrm{b})$. However, the present study is the first one to suggest a selective effect of loss of a bonded partner, as opposed to mere social isolation, on passive stress-coping behavior. Interestingly, separation from a partner for 4 days, regardless of its sex, tended to increase anxiety-related behavior on the elevated plus-maze in male prairie voles, consistent with previous findings after a $24 \mathrm{~h}$ separation (Stowe et al, 2005).

There are two caveats of the present study that must be considered in the interpretation of this data. First, it is important to note that the present study does not 
differentiate the effects of pair bond disruption in general $v s$ loss of a potential sexual partner. However, under the pairing conditions used in this study, mating begins $24-48 \mathrm{~h}$ following pairing and extends for only $24 \mathrm{~h}$ (Roberts et al, 1998), therefore mating would have ceased by the time of the separation. We did not quantify mating during the 5 day cohabitation period, but it should be noted that even $24 \mathrm{~h}$ of cohabitation without mating is sufficient for the development of a partner preference (Williams et al, 1992). Thus, this suggests that it is the disruption of the pair bond, and not the loss of a potential sexual partner, that is altering the coping behavior. Future studies can address this issue by pharmacologically blocking partner preference formation and examining coping behavior following separation from the partner. A second caveat is that the males in the paired group cohabitated with the females for several days longer than the males in the separated group. However, as mating does not occur after the fourth day of cohabitation, and there were no differences in coping behavior between the males that remained paired with their female partner and the male either paired or separated from a sibling partner, it is unlikely the mere difference in duration of cohabitation with the female resulted in the increase in passive coping behavior.

Evidence from both clinical and basic research indicates that the development of depression may arise from a dysregulation of the CRF system (Holsboer and Barden, 1996; Nemeroff, 1996; Keck, 2006). Animal models of stressinduced anhedonia show increased CRF content in the BNST (Stout et al, 2000), whereas passive coping behaviors in the FST can be reversed with CRF-R antagonists (Griebel et al, 2002; for review see Bale, 2005). Interestingly, there is growing evidence supporting the use of CRF-R1 antagonists as antidepressants (Holsboer, 1999; Bale, 2005; Zobel et al, 2000; but see Binneman et al, 2008).

On the basis of these data, we predicted that the passivecoping behaviors as indicators of depressive-like behavior arising from separation from a female partner may be linked to CRF activity. Constantly blocking CRF-R1 and/or $\mathrm{R} 2$ during the isolation period prevented the emergence of passive coping behavior, supporting our hypothesis. Interestingly, these treatments did not decrease passive stress coping in voles that remained with the female partner, which is probably due to the fact that in these groups the time spent on floating and immobility in the FST and the TST, respectively, was already low. More importantly, despite the fact that partner preference formation is facilitated by exposure to stressors (DeVries et al, 1996) or central infusions of CRF (DeVries et al, 2002; Lim et al, 2007), CRF-R antagonist given after partner preference formation did not disrupt partner preferences (Experiment D). The preservation of the partner preferences demonstrates that social memory of the partner was not affected by the CRF-R antagonist treatment (Heinrichs, 2003).

We had initially predicted that CRF mRNA content might also be the highest in animals separated from a female. However, this was not the case - males that remained with a female and males that were isolated from a female both showed increased CRF mRNA content in the mBNST relative to males paired or separated from a male sibling. This finding suggests that pairing with a female partner, including sexual experience, alters the CRF tone, perhaps priming the brain to quickly respond to social stressors. Also, a lack of increased CRF mRNA expression in other brain regions emphasizes the selectivity of the effects on CRF expression.

The upregulation of the CRF mRNA in the mBNST in pair-bonded males and the lack of increased passive stresscoping behavior in separated males with long-term CRF-R antagonism together provide solid evidence that the CRF system are important in the passive stress-coping behavior following isolation from an opposite sex bonded partner. Which CRF ligands (CRF or the urocortins) and which CRF receptor populations mediate social loss-induced passive stress-coping behavior remains to be investigated. However, our findings that both CRF-R1 and CRF-R2 mediate stress responses are consistent with recent findings. Bakshi et al (2002) showed that both CRF-R1 and -R2 mediate stress responses in independent brain areas and Lim et al (2007) that both CRF-R1 and CRF-R2 in the nucleus accumbens are necessary for CRF-induced partner preference formation in prairie voles.

HPA axis activity is used as a measure of the physiological stress status. An acute increase of these parameters is traditionally viewed as a stress response (Levine et al, 1989), whereas an elevation in basal corticosterone (Albeck et al, 1997; Zelena et al, 1999) and adrenal hypertrophy (Biondi and Zannino, 1997; Reber et al, 2006, 2007) are established markers for chronic stress. In support, our experiments revealed basal plasma corticosterone levels to be significantly higher in male voles separated from a female compared to all other groups. Moreover, an increased weight of the adrenal glands, the source of corticosterone and adrenaline, was found in males 5 days after separation from a female, thereby giving further evidence of a chronically upregulated basal HPA axis in male voles separated from the bonded female partner.

The finding of elevated corticosterone levels exclusively in males separated from the female bonded partner is in line with studies showing that contact with a female suppresses basal HPA axis activity in both naïve and pair-bonded male voles (DeVries et al, 1997). Our results also support earlier reports that baseline corticosteroids are elevated following separation from a female partner in various species (Crawley, 1984; Mendoza and Mason, 1986; Ziegler et al, 1995; Castro and Matt, 1997; Norcross and Newman, 1999), including prairie voles (Carter et al, 1995). Interestingly, in earlier studies short-term separation from a sibling was reported to increase basal levels of corticosterone in 40-dayold female prairie voles (Kim and Kirkpatrick, 1996) as well as in juvenile voles of both sexes (Ruscio et al, 2007). Thus, it seems that in adult female voles the loss of social support by a conspecific partner of the same sex has strong physiological (Kim and Kirkpatrick, 1996) and emotional (Grippo et al, 2007a, b) effects whereas in males only the loss of a bonded female partner results in alterations of these parameters.

Surprisingly, the elevated corticosterone in this study was not accompanied by increased CRF mRNA content in the hypothalamic PVN. One possibility is that AVP released from the parvocellular neurons of the PVN may act synergistically with CRF on ACTH-containing cells of the pituitary under stressful conditions (Gillies et al, 1982; Aguilera, 1994). In the present study, the long-term 
separation from the female partner might act as a chronic stressor, during which AVP appears to become the predominant regulator of HPA function (Aguilera, 1994) whereas CRF mRNA expression can be unchanged depending on the stressor (Aguilera and Rabadan-Diehl, 2000).

In conclusion, in the monogamous male prairie vole, 4-5 days of separation from the bonded female partner only, but not social isolation per se as seen in female voles (Grippo et al, 2007a,b), results in the emergence of passive stresscoping behavior as well as increased HPA axis activity. Although it is difficult to interpret increased passive stresscoping behavior in voles, antidepressants reduce this behavior in the FST and TST in other species, suggesting that it is relevant to depressive-like behavior in these species. The combined increase in passive stress-coping behavior and in HPA axis activity in males in the present study are, however, consistent with the hypothesis that separation from a bonded mating partner is aversive in prairie voles, as it is in humans. Although the emergence of passive stress-coping behavior and increased HPA activity following the loss of a bonded female partner is intuitively maladaptive, we speculate that this phenomenon may actually be the by-product of an adaptive bidimensional integrative emotional system (eg reward/aversion) that is fundamental to the formation and preservation of enduring bonds (Panksepp et al, 1997). Although CRF-R activation is apparently not necessary for the display of a partner preference, activation of this system following separation from the mating partner may act to preserve the established pair by maintaining contact. Thus, the CRF system may compliment the reinforcing effects of other neuropeptides systems (eg oxytocin and vasopressin) which are thought to be critical to pair-bond formation. On the basis of our results we believe that prairie voles represent an important rodent model that will provide us with unique insights into the neurobiology of the loss of a bonded partner which may be relevant to grieving and bereavement in humans.

\section{ACKNOWLEDGEMENTS}

We thank Dr Michael Owens for providing the CP-154,526; Dr Lisa Stanek, Mrs Lorra Mathews (Atlanta), Dr Hinrich Sass, and Mrs Luxiola Gonzales (Regensburg) for expert technical assistance, and DAAD/National Science Foundation (IDN, LJY), National Institute of Mental Health $\mathrm{MH}$ 077776, MH 064692 (LJY), NCRR RR00165 to Yerkes National Primate Center, and Vielberth-Foundation (University of Regensburg) and VolkswagenStiftung (IDN) for financial support.

\section{DISCLOSURE/CONFLICT OF INTEREST}

The authors declare that, except for income received from their primary employer, no financial support or compensation has been received from any individual or corporate entity over the past 3 years for research or professional service others than stated below and that there are no personal financial holdings that could be perceived as constituting a potential conflict of interest.

Dr Neumann's research was funded by the DFG, BMBF, DAAD, Vielberth-Foundation, and VolkswagenStiftung; financial support for professional service has been received by Organon, Lundbeck, and LaRoche.

Dr Young's research was funded by the National Science Foundation, the National Institute of Health, and Autism Speaks.

\section{REFERENCES}

Aguilera G (1994). Regulation of pituitary ACTH secretion during chronic stress. Front Neuroendocrinol 15: 321-350.

Aguilera G, Rabadan-Diehl C (2000). Vasopressinergic regulation of the hypothalamic-pituitary-adrenal axis: implications for stress adaptation. Regul Pept 96: 23-29.

Albeck DS, McKittrick CR, Blanchard DC, Blanchard RJ, Nikulina J, McEwen BS et al (1997). Chronic social stress alters levels of corticotropin-releasing factor and arginine vasopressin mRNA in rat brain. J Neurosci 17: 4895-4903.

Aragona BJ, Liu Y, Curtis TJ, Stephan FK, Wang ZX (2003). A critical role for nucleus accumbens dopamine in partner preference formation of male prairie voles. J Neurosci 23: 3483-3490.

Aragona BJ, Liu Y, Yu YJ, Curtis JT, Detwiler JM, Insel TR et al (2006). Nucleus accumbens dopamine differentially mediates the formation and maintenance of monogamous pair bonds. Nat Neurosci 9: 133-139.

Aragona BJ, Wang Z (2004). The prairie vole (Microtus ochrogaster): an animal model for behavioral neuroendocrine research on pair bonding. ILAR J 45: 35-45.

Armario A, Galvadà A, Martí O (1988). Forced swimming test in rats: effect of desipramine administration and the period of exposure to the test on struggling behaviour, swimming, immobility and defecation rate. Eur J Pharmacol 158: 207-212.

Bakshi VP, Smith-Roe S, Newman SM, Grigoriadis DE, Kalin NH (2002). Reduction of stress-induced behavior by antagonism of corticotropin-releasing hormone $2(\mathrm{CRH} 2)$ receptors in lateral septum or CRH1 receptors in amygdala. J Neurosci 22: 2926-2935.

Bale TL (2005). Sensitivity to stress: dysregulation of CRF pathways and disease development. Horm Behav 48: 1-10.

Behan DP, Grigoriadis DE, Lovenberg T, Chalmers D, Heinrichs S, Liaw C et al (1996). Neurobiology of corticotropin releasing factor (CRF) receptors and CRF-binding protein: implications for the treatment of CNS disorders. Mol Psychiatry 1: 265-277.

Binneman B, Feltner D, Kolluri S, Shi Y, Qiu R, Stiger T (2008). A 6-week randomized, placebo-controlled trial of CP-316, 311 (a selective CRH1 antagonist) in the treatment of major depression. Am J Psychiatry 165: 617-620.

Biondi M, Picardi A (1996). Clinical and biological aspects of bereavement and loss-induced depression: a reappraisal. Psychother Psychosom 65: 229-245.

Biondi M, Zannino LG (1997). Psychological stress, neuroimmunomodulation, and susceptibility to infectious diseases in animals and man: a review. Psychother Psychosom 66: 3-26.

Borsini F, Meli A (1988). Is the forced swimming test a suitable model for revealing antidepressant activity? Psychopharmacology 94: 147-160.

Bosch OJ, Meddle SL, Beiderbeck DI, Douglas AJ, Neumann ID (2005). Brain oxytocin correlates with maternal aggression: link to anxiety. J Neurosci 25: 6807-6815.

Capitanio JP, Mendoza SP, Lerche NW (1998). Individual differences in peripheral blood immunological and hormonal measures in adult male rhesus macaques (Macaca mulatta): evidence for temporal and situational consistency. Am J Primatol 44: 29-41.

Carter CS, DeVries AC, Getz LL (1995). Physiological substrates of mammalian monogamy: the prairie vole model. Neurosci Biobehav Rev 19: 303-314. 
Carter CS, Getz LL (1993). Monogamy and the prairie vole. Sci Am 268: $100-106$.

Castro WLR, Matt KS (1997). Neuroendocrine correlates of separation stress in the Siberian dwarf hamster (Phodopus sungorus). Physiol Behav 61: 477-484.

Crawley JN (1984). Evaluation of a proposed hamster separation model of depression. Psychiatry Res 11: 35-47.

Cryan JF, Mombereau C (2004). In search of a depressed mouse: utility of models for studying depression-related behavior in genetically modified mice. Mol Psychiatry 9: 326-357.

Cryan JF, Valentino RJ, Lucki I (2005). Assessing substrates underlying the behavioral effects of antidepressants using the modified rat forced swimming test. Neurosci Biobehav Rev 29: 547-569.

DeVries AC (2002). Interaction among social environment, the hypothalamic-pituitary-adrenal axis, and behavior. Horm Behav 41: 405-413.

DeVries AC, DeVries MB, Taymans SE, Carter CS (1996). The effects of stress on social preferences are sexually dimorphic in prairie voles. Proc Natl Acad Sci USA 93: 11980-11984.

DeVries AC, Glasper ER, Detillion CE (2003). Social modulation of stress responses. Physiol Behav 79: 399-407.

DeVries AC, Guptaa T, Cardillo S, Cho M, Carter CS (2002). Corticotropin-releasing factor induces social preferences in male prairie voles. Psychoneuroendocrinology 27: 705-714.

DeVries AC, Taymans SE, Carter CS (1997). Social modulation of blood corticosterone levels in male prairie voles. Ann NY Acad Sci 807: 494-498.

Ebner K, Bosch OJ, Kromer SA, Singewald N, Neumann ID (2005). Release of oxytocin in the rat central amygdala modulates stresscoping behavior and the release of excitatory amino acids. Neuropsychopharmacology 30: 223-230.

Elliot G (1989). Stress and illness. In: Cherin S (ed). Psychosomatic Medicine. International University Press: Madison. pp 45-90.

Gillies GE, Linton EA, Lowry PJ (1982). Corticotropin releasing activity of the new CRF is potentiated several times by vasopressin. Nature 299: 355-357.

Griebel G, Simiand J, Steinberg R, Jung M, Gully D, Roger P et al (2002). 4-(2-Chloro-4-methoxy-5-methylphenyl)- $N$-[(1S)-2-cyclopropyl-1-(3-fluoro-4-methylphenyl)ethyl]5-methyl- $N$-(2-propynyl)-1, 3-thiazol-2-amine hydrochloride (SSR125543A), a potent and selective corticotrophin-releasing factor(1) receptor antagonist. II. Characterization in rodent models of stressrelated disorders. J Pharmacol Exp Ther 301: 333-345.

Grippo AJ, Cushing BS, Carter CS (2007a). Depression-like behavior and stressor-induced neuroendocrine activation in female prairie voles exposed to chronic social isolation. Psychosom Med 69: 149-157.

Grippo AJ, Gerena D, Huang J, Kumar N, Shah M, Ughreja R et al (2007b). Social isolation induces behavioral and neuroendocrine disturbances relevant to depression in female and male prairie voles. Psychoneuroendocrinology 32: 966-980.

Heinrichs SC (2003). Modulation of social learning in rats by brain corticotropin-releasing factor. Brain Res 994: 107-114.

Hendrie CA, Eilam D, Weiss SM (1997). Effects of diazepam and buspirone on the behaviour of wild voles (Microtus socialis) in two models of anxiety. Pharmacol Biochem Behav 58: 573-576.

Hodgson RA, Higgins GA, Guthrie DH, Lu SX, Pond AJ, Mullins $\mathrm{DE}$ et al (2007). Comparison of the V1b antagonist, SSR149415, and the CRF1 antagonist, CP-154, 526, in rodent models of anxiety and depression. Pharmacol Biochem Behav 86: 431-440.

Holsboer F (1999). The rationale for corticotropin-releasing hormone receptor (CRH-R) antagonists to treat depression and anxiety. J Psychiatr Res 33: 181-214.

Holsboer F, Barden N (1996). Antidepressants and hypothalamicpituitary-adrenocortical regulation. Endocr Rev 17: 187-205.

House A, Dennis M, Mogridge L, Hawton K, Warlow C (1990). Life events and difficulties preceding stroke. J Neurol Neurosurg Psychiatry 53: 1024-1028.
Insel TR, Preston S, Winslow JT (1995). Mating in the monogamous male: behavioral consequences. Physiol Behav 57: 615-627.

Keck ME (2006). Corticotropin-releasing factor, vasopressin and receptor systems in depression and anxiety. Amino Acids 31: 241-250.

Kikusui T, Winslow JT, Mori Y (2006). Social buffering: relief from stress and anxiety. Philos Trans R Soc Lond B Biol Sci 361: 2215-2228.

Kim JW, Kirkpatrick B (1996). Social isolation in animal models of relevance to neuropsychiatric disorders. Biol Psychiatry 40: 918-922.

Kirschbaum C, Klauer T, Filipp S, Hellhammer D (1995). Sexspecific effects of social support on cortisol and subjective responses to acute psychological stress. Psychosom Med 57: 23-31.

Kishimoto T, Radulovic J, Radulovic M, Lin CR, Schrick C, Hooshmand F et al (2000). Deletion of Crhr2 reveals an anxiolytic role for corticotropin-releasing hormone receptor-2. Nat Genet 24: 415-419.

Levine S, Wiener S, Coe C (1989). The psychoneuroendocrinology of stress: a psychobiological perspective. In: Brush FR, Levine SE (eds). Psychoendocrinology. Academic Press: San Diego. pp 341-377.

Liebsch G, Landgraf R, Engelmann M, Lörscher P, Holsboer F (1999). Differential behavioural effects of chronic infusion of $\mathrm{CRH} 1$ and $\mathrm{CRH} 2$ receptor antisense oligonucleotides into the rat brain. J Psychiatr Res 33: 153-163.

Liebsch G, Landgraf R, Gerstberger R, Probst JC, Wotjak CT, Engelmann $\mathrm{M}$ et al (1995). Chronic infusion of a $\mathrm{CRH}_{1}$ receptor antisense oligodeoxynucleotide into the central nucleus of the amygdala reduced anxiety-related behavior in socially defeated rats. Regul Pept 59: 229-239.

Liebsch G, Montkowski A, Holsboer F, Landgraf R (1998). Behavioural profiles of two Wistar rat lines selectively bred for high or low anxiety-related behaviour. Behav Brain Res 94: 301-310.

Lim MM, Liu Y, Ryabinin AE, Bai Y, Wang Z, Young LJ (2007). CRF receptors in the nucleus accumbens modulate partner preference in prairie voles. Horm Behav 51: 508-515.

Martí J, Armario A (1993). Effects of diazepam and desipramine in the forced swimming test: influence of previous experience with situation. Eur J Pharmacol 236: 295-299.

Mendoza SP, Mason WA (1986). Contrasting responses to intruders and to involuntary separation by monogamous and polygynous new world monkeys. Physiol Behav 38: 795-801.

Nair HP, Young LJ (2006). Vasopressin and pair-bond formation: genes to brain to behavior. Physiology 21: 146-152.

Nemeroff CB (1996). The corticotropin-releasing factor (CRF) hypothesis of depression: new findings and new directions. Mol Psychiatry 1: 336-342.

Neumann ID, Johnstone HA, Hatzinger M, Liebsch G, Shipston M, Russell JA et al (1998). Attenuated neuroendocrine responses to emotional and physical stressors in pregnant rats involve adenohypophysial changes. J Physiol 508: 289-300.

Norcross J, Newman J (1999). Effects of separation and novelty on distress vocalizations and cortisol in the common marmoset (Callithrix jacchus). Am J Primatol 47: 209-222.

Oshima A, Flachskamm C, Reul JM, Holsboer F, Linthorst AC (2003). Altered serotonergic neurotransmission but normal hypothalamic-pituitary-adrenocortical axis activity in mice chronically treated with the corticotropin-releasing hormone receptor type 1 antagonist NBI 30775. Neuropsychopharmacology 28: $2148-2159$.

Overstreet DH, Keeney A, Hogg S (2004). Antidepressant effects of citalopram and CRF receptor antagonist CP-154,526 in a rat model of depression. Eur J Pharmacol 492: 195-201.

Overstreet DH, Stemmelin J, Griebel G (2008). Confirmation of antidepressant potential of the selective beta3 adrenoceptor 
agonist amibegron in an animal model of depression. Pharmacol Biochem Behav 89: 623-626.

Panksepp J, Nelson E, Bekkedal M (1997). Brain systems for the mediation of social separation-distress and social-reward. Evolutionary antecedents and neuropeptide intermediaries. Ann NY Acad Sci 807: 78-100.

Pellow S, Chopin P, File SE, Briley M (1985). Validation of open:closed arm entries in an elevated plus-maze as a measure of anxiety in the rat. J Neurosci Methods 14: 149-167.

Pitkow LJ, Sharer CA, Ren X, Insel TR, Terwilliger EF, Young LJ (2001). Facilitation of affiliation and pair-bond formation by vasopressin receptor gene transfer into the ventral forebrain of a monogamous vole. J Neurosci 21: 7392-7396.

Porsolt RD, LePichon M, Jalfre M (1977). Depression: a new animal model sensitive to antidepressant treatment. Nature 266: 730-732.

Reber SO, Birkeneder L, Veenema AH, Obermeier F, Falk W, Straub RH et al (2007). Adrenal insufficiency and colonic inflammation after a novel chronic psycho-social stress paradigm in mice: implications and mechanisms. Endocrinology 148: $670-682$

Reber SO, Obermeier F, Straub RH, Falk W, Neumann ID (2006). Chronic intermittent psychosocial stress (social defeat/overcrowding) in mice increases the severity of an acute DSSinduced colitis and impairs regeneration. Endocrinology 147: 4968-4976.

Ressler KJ, Paschall G, Zhou XL, Davis M (2002). Regulation of synaptic plasticity genes during consolidation of fear conditioning. J Neurosci 22: 7892-7902.

Roberts RL, Cushing BS, Carter CS (1998). Intraspecific variation in the induction of female sexual receptivity in prairie voles. Physiol Behav 64: 209-212.

Ruscio MG, Sweeny T, Hazelton J, Suppatkul P, Carter SC (2007). Social environment regulates corticotropin releasing factor, corticosterone and vasopressin in juvenile prairie voles. Horm Behav 51: 54-61.

Sachser N, Durschlag M, Hirzel D (1998). Social relationships and the management of stress. Psychoneuroendocrinology 23: 891-904.

Shear K, Shair H (2005). Attachment, loss, and complicated grief. Dev Psychobiol 47: 253-267.

Steru L, Chermat R, Thierry B, Simon P (1985). The tail suspension test: a new method for screening antidepressants in mice. Psychopharmacology 85: 367-370.

Stout SC, Mortas P, Owens MJ, Nemeroff CB, Moreau J (2000). Increased corticotropin-releasing factor concentrations in the bed nucleus of the stria terminalis of anhedonic rats. Eur $J$ Pharmacol 401: 39-46.

Stowe JR, Liu Y, Curtis JT, Freeman ME, Wang Z (2005). Species differences in anxiety-related responses in male prairie and meadow voles: the effects of social isolation. Physiol Behav 86: 369-378.

Thorsteinsson E, James J (1999). A meta-analysis of the effects of experimental manipulations of social support during laboratory stress. Psychol Health 14: 869-886.

Timpl P, Spanagel R, Sillaber I, Kresse A, Reul JM, Stalla GK et al (1998). Impaired stress response and reduced anxiety in mice lacking a functional corticotropin-releasing hormone receptor 1. Nat Genet 19: 162-166.

Torner L, Toschi N, Pohlinger A, Landgraf R, Neumann ID (2001). Anxiolytic and anti-stress effects of brain prolactin: improved efficacy of antisense targeting of the prolactin receptor by molecular modeling. J Neurosci 21: 3207-3214.

Uchino B, Cacioppo JT, Kiecolt-Glaser JK (1996). The relationship between social support and physiological processes: a review with emphasis on underlying mechanisms and implications for health. Psychol Bull 119: 488-531.

Watanabe M, Irie M, Kobayashi F (2004). Relationship between effort-reward imbalance, low social support and depressive state among Japanese male workers. J Occup Health 46: 78-81.

Williams JR, Catania KC, Carter CS (1992). Development of partner preferences in female prairie voles (Microtus ochrogaster): the role of social and sexual experience. Horm Behav 26: 339-349.

Winslow JT, Hastings N, Carter CS, Harbaugh CR, Insel TR (1993). A role for central vasopressin in pair bonding in monogamous prairie voles. Nature 365: 545-548.

Young LJ, Wang Z (2004). The neurobiology of pair bonding. Nat Neurosci 10: 1048-1054.

Zelena D, Haller J, Halasz J, Makara GB (1999). Social stress of variable intensity: physiological and behavioral consequences. Brain Res Bull 48: 297-302.

Ziegler TE, Scheffler G, Snowdon CT (1995). The relationship of cortisol levels to social environment and reproductive functioning in female cotton-top tamarins, Saguinus oedipus. Horm Behav 29: 407-424.

Zisook S, Paulus M, Shuchter SR, Judd LL (1997). The many faces of depression following spousal bereavement. J Affect Disord 45: 85-95.

Zobel AW, Nickel T, Künzel HE, Ackl N, Sonntag A, Ising M et al (2000). Effects of the high-affinity corticotropin-releasing hormone receptor 1 antagonist R121919 in major depression: the first 20 patients treated. J Psychiatr Res 34: 171-181.

Supplementary Information accompanies the paper on the Neuropsychopharmacology website (http://www.nature.com/npp) 